\title{
An Improved UPFC Control to Enhance Power System Stability
}

\author{
Ashwin Kumar Sahoo (Corresponding Author) \\ Department of Electrical and Electronics Engineering \\ SSN Institutions, OMR, Kalavakkam, TN, India - 603110 \\ E-mail: ashwinsahoo@ssn.edu.in Tel/Fax: (+91)044 - 2747 4844/45/46
}

Dr. S. S Dash

Department of Electrical and Electronics Engineering

SRM University, Katankulathur, Tamil Nadu, India - 603203

E-mail:munu_dash_2k@yahoo.com

Dr. T. Thyagarajan

Professor, Department of Instrumentation Engineering

MIT, Anna University, Chennai, India

E-mail: thyagu_vel@yahoo.co.in

\begin{abstract}
This paper presents an application of Single- Input Fuzzy Logic Controller (SFLC) to determine the control signal of Unified Power Flow Controller (UPFC) for improvement of power system stability. This compensation scheme relevant to Flexible AC Transmission systems (FACTS) technology is used worldwide to improve system dynamic performance. The UPFC is one of the most versatile flexible AC transmission system devices, which can be used to control the active and reactive power flows in a transmission line by injecting a variable voltage in series and reactive current in shunt. The SFLC uses only one input variable which is called as signed distance. The SFLC has many advantages: The total number of rules is greatly reduced compared to existing fuzzy logic controllers (FLC's), and hence, generation and tuning of control rules are much easier. The proposed control method is applied to Single Machine Infinite Bus (SMIB) System to improve the transient stability.
\end{abstract}

Keywords: FACTS, Power system stability, Single Input Fuzzy Logic Controller, UPFC

\section{Nomenclature}

$\delta \quad-\quad$ Rotor angle with respect to the infinite bus system voltage

$\mathrm{M}$ - Effective inertia constant

$\mathrm{E}_{\mathrm{q}}^{\prime} \quad$ - Transient q-axis voltage

$\mathrm{x}_{\mathrm{d}}-\mathrm{d}$-axis reactance

$x_{q}-\quad q$-axis reactance

$\mathrm{x}_{\mathrm{d}}^{\prime}-\quad \mathrm{d}$-axis transient reactance

$\mathrm{E}_{\mathrm{fd}}$ - Direct excitation voltage

$\mathrm{T}_{\mathrm{do}}^{\prime}-\quad$ Equivalent transient rotor time constant

$\mathrm{P}, \mathrm{Q} \quad$ - $\quad$ Active and reactive power

$\mathrm{w}_{\mathrm{b}}$ - Base angular frequency

\section{Introduction}

The advent of advanced power electronics technology has enabled the use of voltage source inverters (VSI) at both the transmission and distribution levels. A stream of VSI based systems such as UPFC, Static Synchronous Compensator (STATCOM), and Dynamic Voltage Restorer (DVR) has made FACTS (Gyugyi L, 1994; Narain G. Hingorani and Laszlo Gyugyi, 2000) possible. Successful applications of FACTS equipment for power flow control, voltage control and transient stability improvement have been reported in the literatures (Eskandar Gholipour and Shahrokh Saadate, 2005; Nabavi-Niaki and M. R. Iravani, 1996; B. Renz et al., 1999; S. Kannan 
et al., 2004).

In recent years increasing interest has been seen in applying fuzzy theory (C.C. Lee, 1990) to controller design in many engineering fields. This paper focuses on the use of UPFC with SFLC's (Byung-Jae Choi et al., 2000) for the Shunt and Series Inverter of the UPFC for transient stability improvement and voltage control of power system. The principal function of the UPFC is to control the flow of real and reactive power by injecting a voltage in series with the transmission line. The UPFC consists of two solid-state voltage source inverters (VSIs) connected by a common DC link that includes a storage capacitor (shown in Figure 1). The first inverter (shunt inverter), known as a STATCOM (Static Synchronous Compensator), injects an almost sinusoidal current of variable magnitude, at the point of connection. The second inverter (series inverter), known as SSSC (Static Synchronous Series Compensator), provides the main functionality of the UPFC by injecting an AC voltage, Vc, with a controllable magnitude $\left(0 \leq \mathrm{V}_{\mathrm{c}} \leq \mathrm{V}_{\mathrm{c}}^{\max }\right)$ and phase angle $\left(\geq 0^{0}, \leq 360^{\circ}\right)$. Thus, the complete configuration operates as an ideal $\mathrm{AC}$ to $\mathrm{AC}$ power converter in which real power can flow freely in either direction between the AC terminals of the two inverters. The phasor diagram in Figure 1 illustrates that the UPFC is able to inject a controlled series voltage $\mathrm{Vc}$ into the transmission line. Thus, the magnitude and angle between the sending and receiving end of the transmission line are modulated resulting in power flow control in the transmission line. Therefore, the active power controller can significantly affect the level of reactive power flow and vice versa. In order to improve the dynamic performance and reduce the interaction between the active and reactive power control, the watt-var decoupled control algorithm has been proposed (Padiyar K R and Kulkarni A M, 1998). In addition, each inverter can independently modulate reactive power at its own AC output terminal. Thus different controllers have been designed for the UPFC for reliable and fast operation. As discussed earlier the UPFC has two VSIs connected back to back. One can take the advantages to utilize any one of the VSI by switching off the second one. The Shunt inverter injects an almost sinusoidal current of magnitude, at the point of connection. There are two control objectives in UPFC control, i.e., Shunt inverter control and Series inverter control. For the Shunt inverter there are two voltage regulators designed for this purpose: AC bus voltage regulators and DC voltage regulator. Conventionally, both the regulators are proportional integral (PI) type cascaded controllers (Padiyar K R and Kulkarni A M, 1998). The Series inverter is controlled by two PI controllers. The modeling and control design are usually carried in the standard synchronous d-q frame (Anderson PM, Fouad AA., 1994; Bergen AR. 1986). Although, the PI control structure yields good performance, it is not very much effective for all operating conditions because of the unsuitability of one set of PI gains for all four regulators of the cascade controllers and the inherent coupling between the $\mathrm{d}$ and $\mathrm{q}$ axis. In essence, since the complete model is highly nonlinear, the linear approach obviously does not offer better dynamic decoupling.

The SFLC (Byung-Jae Choi et al., 2000) design has been tested by computer simulations under various types of large disturbances occurring in a single-machine infinite-bus power system equipped with AVR and PSS. The comparison of the results with conventional cascaded control structure of UPFC reveals the supremacy of the SFLC.

The remainder of the paper is organized as follows. At first, the modelling of synchronous generator along with AVR and PSS, modelling of UPFC, and the conventional control scheme of a UPFC have been described along with a study of the simulation results under transient disturbance. Subsequently, the design of the proposed SFLC for the Shunt and Series inverter of UPFC has been derived followed by a comparative evaluation of this new controller's performance via computer simulation results. Finally, the conclusions of this study are reported. The various parameters of the power system and the controllers are listed in the Appendix.

\section{Mathematical Model of UPFC and Conventional Control Schemes}

Single-machine infinite-bus power system considered in this work. The load and the UPFC are connected at the load bus located between the generator bus and the infinite-bus. The mathematical models for the system components along with their control systems are described as follows. The nomenclature is provided at the beginning of the paper.

\subsection{Synchronous Generator Modeling}

The synchronous generator is described by a third-order nonlinear mathematical model given by:

$$
\begin{aligned}
& \frac{\mathrm{d} \delta}{\mathrm{dt}}=\Delta \omega \\
& \frac{\mathrm{d} \Delta \omega}{\mathrm{dt}}=\frac{1}{\mathrm{M}}\left[\mathrm{P}_{\mathrm{m}}-\mathrm{E}_{\mathrm{q}}^{\prime} \mathrm{i}_{\mathrm{q}}-\left(\mathrm{x}_{\mathrm{q}}-\mathrm{x}_{\mathrm{d}}^{\prime}\right) \mathrm{i}_{\mathrm{d}} \mathrm{i}_{\mathrm{q}}\right]
\end{aligned}
$$


$\frac{\mathrm{dE}_{\mathrm{q}}^{\prime}}{\mathrm{dt}}=\frac{1}{\mathrm{~T}_{\mathrm{do}}^{\prime}}\left[\mathrm{E}_{\mathrm{fd}}-\mathrm{E}_{\mathrm{q}}^{\prime}-\left(\mathrm{x}_{\mathrm{d}}-\mathrm{x}_{\mathrm{d}}^{\prime}\right) \mathrm{i}_{\mathrm{d}}\right]$

Where $\Delta \delta=\delta-\delta_{0}$ and $\Delta \omega=\omega-\omega_{0}$.

\subsection{AVR Exciter and PSS}

The excitation system of the generator consists of a simple automatic voltage regulator (AVR) along with a supplementary power system stabilizer (PSS). The complete AVR + PSS control system is shown in Figure 2.

\subsection{Dynamical Modeling of UPFC}

Figure 3 shows the equivalent circuit model of a power system equipped with a UPFC. The series and shunt VSIs are represented by controllable voltage sources $V_{c}$ and $V_{p}$, respectively. $R_{p}$ and $L_{p}$ represent the resistance and leakage reactance of the shunt transformer.

The dynamic model of UPFC is derived by performing standard d-q transformation of the current through the shunt transformer and series transformer. They are as given below ( $\omega$ is the angular frequency of the voltages and currents).

\section{Shunt Inverter:}

$$
\begin{gathered}
\frac{\mathrm{di}_{\mathrm{pd}}}{\mathrm{dt}}=-\frac{\mathrm{R}_{\mathrm{p}}}{\mathrm{L}_{\mathrm{p}}} \mathrm{i}_{\mathrm{pd}}+\omega \mathrm{i}_{\mathrm{pq}}+\frac{1}{\mathrm{~L}_{\mathrm{p}}}\left(\mathrm{V}_{\mathrm{sd}}-\mathrm{V}_{\mathrm{pd}}\right) \\
\frac{\mathrm{di} \mathrm{pq}_{\mathrm{pq}}}{\mathrm{dt}}=-\frac{\mathrm{R}_{\mathrm{p}}}{\mathrm{L}_{\mathrm{p}}} \mathrm{i}_{\mathrm{pq}}-\omega \mathrm{i}_{\mathrm{pd}}+\frac{1}{\mathrm{~L}_{\mathrm{p}}}\left(\mathrm{V}_{\mathrm{sq}}-\mathrm{V}_{\mathrm{pq}}\right)
\end{gathered}
$$

Series Inverter:

$$
\begin{aligned}
& \frac{\mathrm{di}_{\mathrm{bd}}}{\mathrm{dt}}=-\frac{\mathrm{w}_{\mathrm{b}} \mathrm{r}_{\mathrm{e}}}{\mathrm{x}_{\mathrm{e}}} \mathrm{i}_{\mathrm{bd}}+\omega \mathrm{i}_{\mathrm{bq}}+\frac{\mathrm{w}_{\mathrm{b}}}{\mathrm{x}_{\mathrm{e}}}\left(\mathrm{V}_{\mathrm{ud}}-\mathrm{V}_{\mathrm{b}} \sin \delta\right) \\
& \frac{\mathrm{di}_{\mathrm{bq}}}{\mathrm{dt}}=\frac{\mathrm{w}_{\mathrm{b}} \mathrm{r}_{\mathrm{e}}}{\mathrm{x}_{\mathrm{e}}} \mathrm{i}_{\mathrm{bq}}-\omega \mathrm{i}_{\mathrm{bd}}+\frac{\mathrm{w}_{\mathrm{b}}}{\mathrm{x}_{\mathrm{e}}}\left(\mathrm{V}_{\mathrm{uq}}-\mathrm{V}_{\mathrm{b}} \cos \delta\right)
\end{aligned}
$$

For fast voltage control, the net input power should instantaneously meet the charging rate of the capacitor energy. Thus, by power balance,

$$
\begin{aligned}
\mathrm{P}_{\mathrm{s}}-\mathrm{P}_{\mathrm{u}} & =\mathrm{V}_{\mathrm{sd}}\left(\mathrm{i}_{\mathrm{pd}}+\mathrm{i}_{\mathrm{bd}}\right)+\mathrm{V}_{\mathrm{sq}}\left(\mathrm{i}_{\mathrm{pq}}+\mathrm{i}_{\mathrm{bq}}\right)-\left(\mathrm{V}_{\mathrm{ud}} \mathrm{i}_{\mathrm{bd}}+\mathrm{V}_{\mathrm{uq}} \mathrm{i}_{\mathrm{bq}}\right) \\
& =\mathrm{V}_{\mathrm{dc}} \mathrm{i}_{\mathrm{dc}} \\
& =\mathrm{V}_{\mathrm{dc}}\left[\mathrm{C} \frac{\mathrm{dV} \mathrm{V}_{\mathrm{dc}}}{\mathrm{dt}}+\mathrm{g}_{\mathrm{cp}} \mathrm{V}_{\mathrm{dc}}\right]
\end{aligned}
$$

Thus,

$$
\frac{\mathrm{dV}_{\mathrm{dc}}}{\mathrm{dt}}=-\frac{\mathrm{g}_{\mathrm{cp}} \omega}{\mathrm{b}_{\mathrm{cp}}} \mathrm{V}_{\mathrm{dc}}+\frac{1}{\mathrm{CV}_{\mathrm{dc}}}\left[\begin{array}{l}
\mathrm{V}_{\mathrm{sd}} \mathrm{i}_{\mathrm{pd}}+\mathrm{V}_{\mathrm{sq}} \mathrm{i}_{\mathrm{pq}}+ \\
\left(\mathrm{V}_{\mathrm{sd}}-\mathrm{V}_{\mathrm{ud}}\right) \mathrm{i}_{\mathrm{bd}}+\left(\mathrm{V}_{\mathrm{sq}}-\mathrm{V}_{\mathrm{uq}}\right) \mathrm{i}_{\mathrm{bq}}
\end{array}\right]
$$

\subsection{Conventional Control Strategy for UPFC}

The real and reactive power flow in the line can be controlled independently using the series injected voltage which meets almost instantaneously to a command and this voltage is generated by series inverter (SSSC). The shunt inverter (STATCOM) injects a controlled shunt current (indirectly) by varying the shunt inverter voltage. This inverter is responsible for AC-bus and DC-link voltage control (indirectly). Therefore, in the conventional PI control scheme, the control strategies for both the inverters are addressed separately. All the control schemes are discussed in the $\mathrm{d}-\mathrm{q}$ reference frame. 


\subsubsection{Series Inverter Control}

An appropriate series voltage (both magnitude and phase) should be injected for obtaining the commanded active and reactive power flow in the transmission line, i.e., $\left(\mathrm{P}_{\mathrm{u}}, \mathrm{Q}_{\mathrm{u}}\right)$ in this study. The current references are computed from the desired power references and are given by,

$$
\begin{aligned}
& \mathrm{i}_{\mathrm{cd}}^{\text {ref }}=\frac{\mathrm{P}_{\text {ref }} \mathrm{V}_{\mathrm{ud}}-\mathrm{Q}_{\text {ref }} \mathrm{V}_{\mathrm{uq}}}{\mathrm{V}_{\mathrm{u}}^{2}} \\
& \mathrm{i}_{\mathrm{cq}}^{\text {ref }}=\frac{\mathrm{P}_{\text {ref }} \mathrm{V}_{\mathrm{uq}}-\mathrm{Q}_{\text {ref }} \mathrm{V}_{\mathrm{ud}}}{\mathrm{V}_{\mathrm{u}}^{2}}
\end{aligned}
$$

The power flow control is then realized by using appropriately designed controllers to force the line currents to track their respective reference values. Conventionally, two separate PI controllers are used for this purpose. These controllers output the amount of series injected voltages $\left(\mathrm{V}_{\mathrm{cd}}, \mathrm{V}_{\mathrm{cq}}\right)$. The control system diagram is shown in Figure 4.

\subsubsection{Shunt Inverter Control}

As mentioned earlier, the conventional control strategy for this inverter concerns with the control of ac-bus and dc-link voltage. The dual control objectives are met by generating appropriate current reference (for $\mathrm{d}-$ and $\mathrm{q}-$ axis) and then, by regulating those currents. PI controllers are conventionally employed for both the tasks while attempting to decouple the $\mathrm{d}-$ and $\mathrm{q}$-axis current regulators. In this study, the strategy adopted in (Padiyar K R and Kulkarni A M, 1998) for shunt current control has been taken. The inverter current $\left(i_{p}\right)$ is split into real (in phase with ac-bus voltage)

and reactive components. The reference value for the real current is decided so that the capacitor voltage is regulated by power balance. The reference for reactive component is determined by ac-bus voltage regulator. As per the strategy, the original currents in $d-q$ frame $\left(i_{p d}, i_{p q}\right)$ are now

transformed into another frame, $\mathrm{d}^{\prime}-\mathrm{q}^{\prime}$ frame, where $\mathrm{d}^{\prime}-$ axis coincides with the ac-bus voltage (Vs ), as shown in Figure 5.

Thus, in $\mathrm{d}^{\prime}-\mathrm{q}^{\prime}$ frame, the currents $\mathrm{i}_{\mathrm{pd}^{\prime}}$ and $\mathrm{i}_{\mathrm{pq}^{\prime}}$ represent the real and reactive currents and they are given by:

$$
\begin{aligned}
& \mathrm{i}_{\mathrm{pd}^{\prime}}=\mathrm{i}_{\mathrm{pd}} \cos \delta_{\mathrm{s}}+\mathrm{i}_{\mathrm{pq}} \sin \delta_{\mathrm{s}} \\
& \mathrm{i}_{\mathrm{pq}}=\mathrm{i}_{\mathrm{pq}} \cos \delta_{\mathrm{s}}-\mathrm{i}_{\mathrm{pq}} \sin \delta_{\mathrm{s}}
\end{aligned}
$$

Now, for current control, the same procedure has been adopted by re expressing the differential equations (1) and (2) as:

$$
\begin{aligned}
\frac{\mathrm{di}_{\mathrm{pd}}}{\mathrm{dt}} & =-\frac{\mathrm{R}_{\mathrm{p}}}{\mathrm{L}_{\mathrm{p}}} \mathrm{i}_{\mathrm{pd}^{\prime}}+\omega \mathrm{i}_{\mathrm{pq^{ \prime }}}+\frac{1}{\mathrm{~L}_{\mathrm{p}}}\left(\mathrm{V}_{\mathrm{s}}-\mathrm{V}_{\mathrm{pd}}\right) \\
\frac{\mathrm{di}_{\mathrm{pq}^{\prime}}}{\mathrm{dt}} & =-\omega \mathrm{i}_{\mathrm{pd} \mathrm{d}^{\prime}}-\frac{\mathrm{R}_{\mathrm{p}}}{\mathrm{L}_{\mathrm{p}}} \mathrm{i}_{\mathrm{pq}^{\prime}}+\frac{1}{\mathrm{~L}_{\mathrm{p}}}\left(-\mathrm{V}_{\mathrm{pq}}\right)
\end{aligned}
$$

Where $\mathrm{V}_{\mathrm{pd}}=\mathrm{V}_{\mathrm{pd}} \cos \delta \mathrm{s}+\mathrm{V}_{\mathrm{pq}} \sin \delta \mathrm{s}$

$\mathrm{V}_{\mathrm{pq}}=\mathrm{V}_{\mathrm{pq}} \cos \delta_{\mathrm{s}}-\mathrm{V}_{\mathrm{pd}} \sin \delta \mathrm{s}$

And $\omega=\omega_{0}+\frac{d \delta_{s}}{d t}$

The VSI voltages are controlled as follows:

$$
\begin{aligned}
& \mathrm{V}_{\mathrm{pq}^{\prime}}=-\left(\omega \mathrm{L}_{\mathrm{p}} \mathrm{i}_{\mathrm{pd}^{\prime}}+\mathrm{L}_{\mathrm{p}} \mathrm{u}_{\mathrm{q}^{\prime}}\right) \\
& \mathrm{V}_{\mathrm{pd}}=\omega \mathrm{L}_{\mathrm{p}} \mathrm{i}_{\mathrm{pq}^{\prime}}+\mathrm{V}_{\mathrm{s}}-\mathrm{L}_{\mathrm{p}} \mathrm{u}_{\mathrm{d}^{\prime}}
\end{aligned}
$$


By putting the above expressions for $V_{p^{\prime}}$ and $V_{p q^{\prime}}$ in equations (14) and (15), the following set of decoupled equations are obtained.

$$
\begin{aligned}
\frac{d i_{p d^{\prime}}}{d t} & =-\frac{R_{p}}{L_{p}} i_{p d^{\prime}}+u_{d^{\prime}} \\
\frac{d i_{p q^{\prime}}}{d t} & =-\frac{R_{p}}{L_{p}} i_{p q^{\prime}}+u_{q^{\prime}}
\end{aligned}
$$

Conventionally, the control signals $\mathrm{u}_{\mathrm{d}^{\prime}}$ and $\mathrm{u}_{\mathrm{q}^{\prime}}$ are determined by linear PI controllers. The complete cascade control architecture is shown below in Figure 6, where $\mathrm{K}_{\mathrm{ps}}, \mathrm{K}_{\mathrm{is}}, \mathrm{K}_{\mathrm{pc}}, \mathrm{K}_{\mathrm{ic}}, \mathrm{K}_{\mathrm{pq}^{\prime}}, \mathrm{K}_{\mathrm{iq}^{\prime}}, \mathrm{K}_{\mathrm{pd}^{\prime}}$, and $\mathrm{K}_{\mathrm{id}}$ are the respective gains of the PI controllers.

In this study, the above design has been used for demonstration of UPFC control. This approach leads to good control as illustrated by the simulation results shown in Section 4 of this paper. However, it must be emphasized here that the decoupling approach taken in the above is not able to decouple the d-q currents completely because of the coupled equations (19) and (20) and, finally, in the frame transformation from $\mathrm{d}^{\prime}-\mathrm{q}^{\prime}$ to $\mathrm{d}-\mathrm{q}$. Moreover, there are several PI controller gains to be determined for an effective control on the complete system. This obviously demands a lot of trial and error approach. Further, the above decoupling technique does not take into account the coupling resulting through the dc-capacitor voltage. All these difficulties always demand better and deeper modern control engineering approach. Such an approach using SFLC has been proposed in this study. The details of the design algorithm are described in the following section.

\section{Design of SFLC}

The absolute magnitude of the control input is proportional to the distance from the following straight line called the switching line as shown in Figure 7. Different switching lines can be obtained by varying the parameter $\lambda$.

$$
\mathrm{s}_{1}: \dot{\mathrm{e}}+\lambda \mathrm{e}=0
$$

The magnitude of the control input $|\mathrm{u}|$ is approximately proportional to the distance from the main diagonal line as shown in Figure 8. In this work two SFLC have been designed in the same manner for two control signals $u_{d}$ and $\mathrm{u}_{\mathrm{q}}$ for shunt inverters and two SFLC for series inverters. The control inputs above and below the switching line have opposite signs. Now we introduce a new variable called signed distance $\mathrm{d}_{\mathrm{s}}$. In this paper all the conventional PI controllers (series as well as shunt controllers) are replaced by SFLC controllers. So e and e are either derivative of voltage error and voltage error, or derivative of capacitor voltage error or change in capacitor voltage error, it depends upon the SFLC type. So the output $u$ is equal to either $u_{d} / u_{q}$ for shunt controllers or Vcd / Vcq for series controllers.

Let $\mathrm{Q}(e, e)$ be the intersection point of the switching line and line perpendicular to the switching line from an point $\mathrm{P}$ (present operating point) as illustrated in Figure 8. The distance $\mathrm{d} 1$ between $\mathrm{Q}$ and $\mathrm{P}$, can be expressed as:

$$
\mathrm{d} 1=\left[\left(\mathrm{e}-\mathrm{e}_{1}\right)^{2}+\left(\dot{\mathrm{e}}-\dot{\mathrm{e}}_{1}\right)^{2}\right]
$$

Equation (24) can be written in general for any $\left(e^{e}, \dot{e}\right)$

$$
\mathrm{d}_{\mathrm{s}}=\left|\frac{\dot{\mathrm{e}}+\lambda \mathrm{e}}{\sqrt{1+\lambda^{2}}}\right|
$$

Then, the signed distance $\mathrm{d}_{\mathrm{s}}$ is defined for a general point $\mathrm{P}\left({ }^{e}, \dot{e}\right)$ as follows: 


$$
\begin{aligned}
& \mathrm{d}_{\mathrm{s}}=\operatorname{sgn}\left(s_{l}\right) \cdot\left|\frac{\dot{\mathrm{e}}+\lambda \mathrm{e}}{\sqrt{1+\lambda^{2}}}\right|=\frac{\dot{\mathrm{e}}+\lambda \mathrm{e}}{\sqrt{1+\lambda^{2}}} \\
& \operatorname{sgn}\left(\mathrm{s}_{1}\right)=\left\{\begin{array}{l}
1, \text { for }_{1}>0 \\
-1, \text { for }_{1}<0
\end{array}\right\}
\end{aligned}
$$

Since the sign of the control input is negative for $S_{1}>0$ and positive for $\mathrm{S}_{1}<0$ and its absolute magnitude is proportional to the distance from the line $\mathrm{S}_{1}=0$, we conclude that,

$$
\mathrm{u} \alpha-\mathrm{d}_{\mathrm{S}}
$$

Then, a fuzzy rule table can be established on a one - dimensional $(1-D)$ space on $d_{s}$ instead of the $2-D$ space of the phase plane for FLC's with skew - symmetric rule table. That is, the control action can be determined by ds only. So, we call it as SFLC . The rule form for the SFLC is given as follows in table 1.If $d_{s}$ is NB then $u$ is PB.

Where NB-big negative, NS-small negative, NR-Zero, PS-Small positive, PB-positive big. Hence, the number of rules is greatly reduced compared to the case of the conventional FLC's. Furthermore, we can easily add or modify rules for fine control. The defuzzification stage produces the final crisp output of SFLC on the base of fuzzy input. The Root Sum Square (RSS) method is employed for defuzzification.

\section{Simulation results and discussion}

The performance of the UPFC with PI controller for stabilization of synchronous generator is evaluated by computer simulation studies. In the simulation studies UPFC has been connected to load bus of SMIB. The transient performances of the rotor angle, rotor speed deviation are compared in Figure 9 for three phase fault when the generator is operating at $\mathrm{P}=1.2$ p.u. and $\mathrm{Q}=0.85$ p.u.. This study clearly indicates better stabilizing properties of UPFC, particularly the restoration of bus voltages to the pre-disturbance value. A comparison of the system responses for a 3-phase fault at infinite $\operatorname{bus}(\mathrm{P}=1.2$ p.u., $\mathrm{Q}=0.85$ p.u. $)$ which is cleared after $0.1 \mathrm{sec}$ is shown in Figure 10.The transient oscillations in rotor angle and speed exhibit good damping behavior for SFLC compared to cascade PI controllers. This is possible because of nonlinear control of bus voltage, resulting in better power modulation, by SFLC controller for stabilizing the synchronous generator. Similar damped oscillations are also seen in the case of $50 \%$ line switching, for $(\mathrm{P}=1.2$ p.u., $\mathrm{Q}=0.85$ p.u.) in Figure 11 .

All the above simulation results demonstrate the superior performance of the proposed SFLC over the cascade PI controllers for large disturbances like 3-phase fault and line switching.

\section{Conclusion}

The proposed SFLC for UPFC is proved to be very effective and robust in damping power system oscillations and thereby enhancing system transient stability. As illustrated by computer simulation studies, the superior damping of the electromechanical oscillations of the synchronous generator provided by this proposed control strategy over the conventional cascade control approach has been established for a variety of severe transient disturbances. Also the proposed controller can be extended for multi-machine system to provide good damping to electromechanical oscillation inherent in power system .

\section{References}

Anderson PM, Fouad AA. (1994). Power System Control and Stability, New York, IEEE Press.

Bergen AR. (1986). Power System Analysis New Jersey, Prentice-Hall.

B. Renz, A.Keri, A. Mehraban, C. Schauder, E. Stacey, L. Kovalsky, L. Gyugyi and A. Edris. (1999). AEP Unified power flow controller performance, IEEE Trans. on Power Delivery, vol. 14, pp. 1374-1381.

Byung-Jae Choi, Seong-Woo Kwak, and Byung Kook Kim. (2000). Design and Stability Analysis of Single-Input Fuzzy Logic Controller, IEEE Trans. on Systems, Man and Cybernetics,Vol 30, No. 2, pp. 303 309. 
C.C. Lee. (1990). Fuzzy logic in control systems: fuzzy logic controller, Parts I and II, IEEE Trans. On Systems, Man and Cybernetics, SMC-20, pp. 404-435.

Eskandar Gholipour and Shahrokh Saadate. (2005). Improving of Transient Stability of Power Systems Using UPFC, IEEE Trans. On Power Delivery, vol. 20, no. 2, pp. 1677 - 1682.

Gyugyi L. (1994). Dynamic compensation of AC transmission lines by solid-state synchronous voltage sources, IEEE Transactions on Power Delivery, vol. 9, pp. 904 - 911.

Nabavi-Niaki and M. R. Iravani. (1996). Steady-state and dynamic models of unified power flow controller (UPFC) for power system studies," IEEE Trans.on Power Syst., vol. 11, no. 4, pp. 1937-1943.

Narain G. Hingorani, Laszlo Gyugyi. (2000). Understanding FACTS: Concepts and Technology of Flexible AC Transmission Systems, IEEE Press New York.

Padiyar KR, Kulkarni AM. (1998). Control design and simulation of a unified power flow controller, IEEE Transactions on Power Delivery, vol. 13(4), pp. 1348-1354.

S. Kannan, S. Jayram, and M. Salma. (2004). Real and reactive power coordination for a unified power flow controller, IEEE Trans. On Power syst., vol. 19, no. 3, pp. 1454-1461.

\section{Appendix}

System Parameters

a) Power System, AVR, Exciter and PSS

$\mathrm{x}_{\mathrm{d}}=1.9$ p.u., $\mathrm{x}_{\mathrm{q}}=1.6$ p.u, $\mathrm{x}_{\mathrm{d}}^{\prime}=0.17$ p.u., $\mathrm{T}_{\mathrm{do}}^{\prime}=4.314 \mathrm{sec} ., \omega_{0}=100 \pi \mathrm{rad} / \mathrm{sec}, \mathrm{x}_{\mathrm{t} 1}=0.2$ p.u.,

$\mathrm{X}_{\mathrm{e}}=0.2$ p.u.,

$\mathrm{r}_{\mathrm{e}}=0.0, \mathrm{M}=0.03$ p.u., $\mathrm{K}_{\mathrm{e}}=200, \mathrm{~T}_{\mathrm{e}}=0.1 \mathrm{sec}, \mathrm{K}_{\mathrm{pw}}=5, \mathrm{~K}_{\mathrm{iw}}=12, \mathrm{E}_{\mathrm{fd}}^{\max }=6$ p.u., $\mathrm{E}_{\mathrm{fd}}^{\min }=-6$ p.u., $\mathrm{u}_{\mathrm{pss}}^{\max }=$

0.01 p.u., $\mathrm{u}_{\mathrm{pss}}^{\max }=-0.01$ p.u. $\mathrm{K}_{\mathrm{f}}=0.01, \mathrm{~T}_{\mathrm{f}}=0.5 \mathrm{sec}$.

b) Converter parameters

$\mathrm{R}_{\mathrm{p}}=0.04$ p.u., $\omega_{0} \mathrm{~L}_{\mathrm{p}}\left(=\mathrm{x}_{\mathrm{p}}\right)=0.1$ p.u., $\mathrm{R}_{\mathrm{dc}}=150, \mathrm{C}=5000 \mu \mathrm{F}$.

PI Controllers of Shunt inverter

$\mathrm{K}_{\mathrm{ps}}=2, \mathrm{~K}_{\mathrm{is}}=20, \mathrm{~K}_{\mathrm{pc}}=0.5, \mathrm{~K}_{\mathrm{ic}}=2, \mathrm{~K}_{\mathrm{pd}}=50, \mathrm{~K}_{\mathrm{id}}=50 / 0.003, \mathrm{~K}_{\mathrm{pq}}=5, \mathrm{~K}_{\mathrm{iq}}=5 / 0.003$

PI Controllers of Series inverter

$\mathrm{K}_{\mathrm{pa}}=0.1, \mathrm{~K}_{\mathrm{ip}}=1, \mathrm{~K}_{\mathrm{qa}}=0.1, \mathrm{~K}_{\mathrm{iqa}}=1$

Table 1. Rule Table

\begin{tabular}{|r|r|r|r|r|r|}
\hline$d_{\text {s }}$ & NB & NS & ZR & PS & PB \\
\hline $\mathbf{u}$ & PB & PS & ZR & NS & NB \\
\hline
\end{tabular}




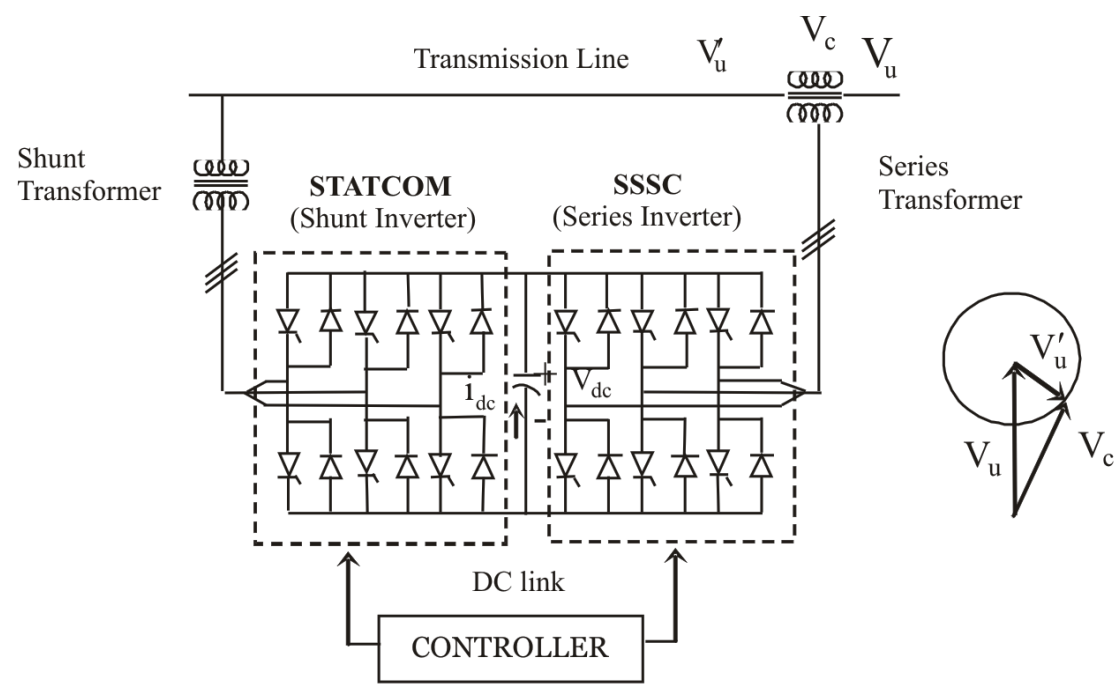

Figure 1. Basic Circuit Configuration of the Unified Power Flow Controller

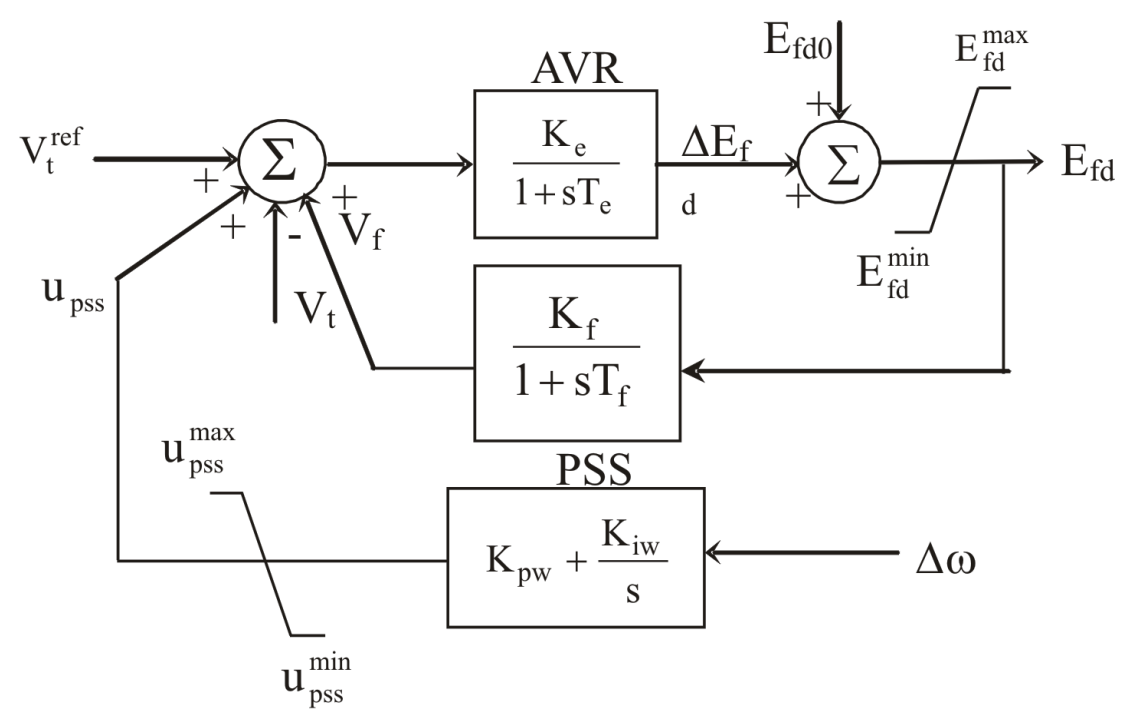

Figure 2. AVR Exciter and PSS Control systems 


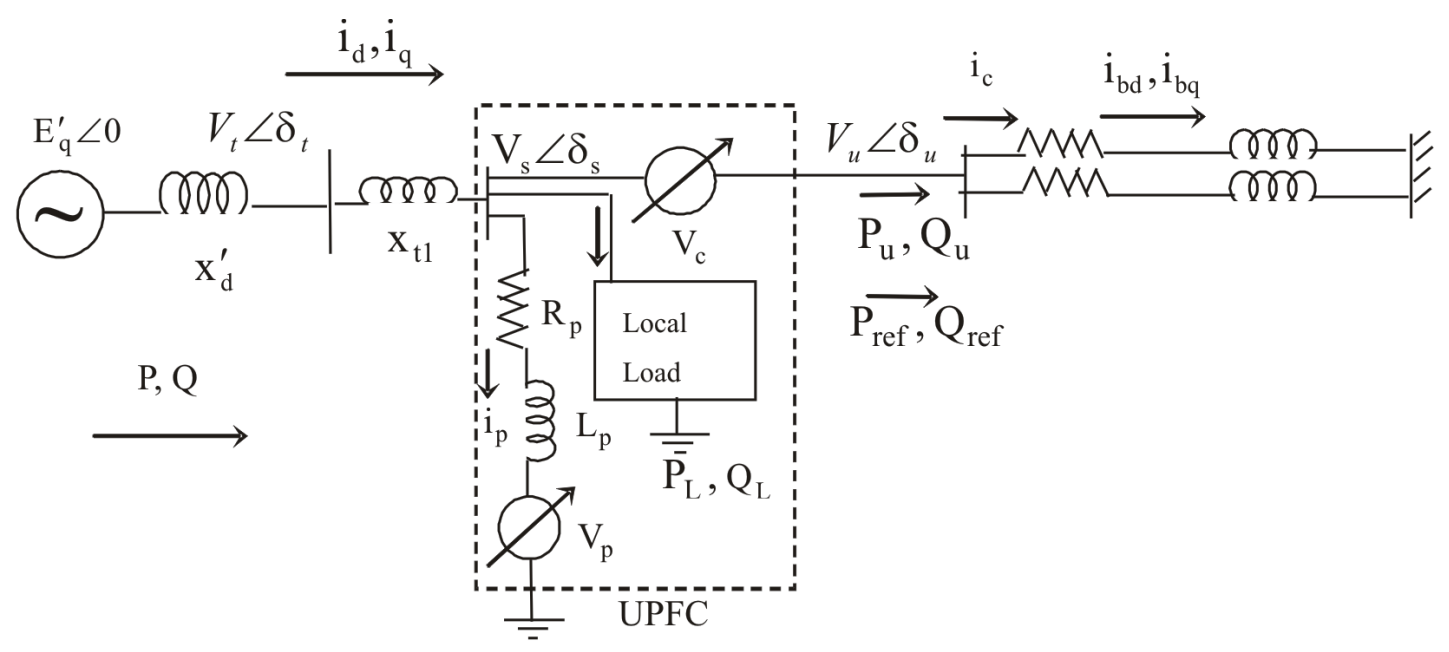

Figure 3. One-line circuit diagram model of UPFC installed in a power system

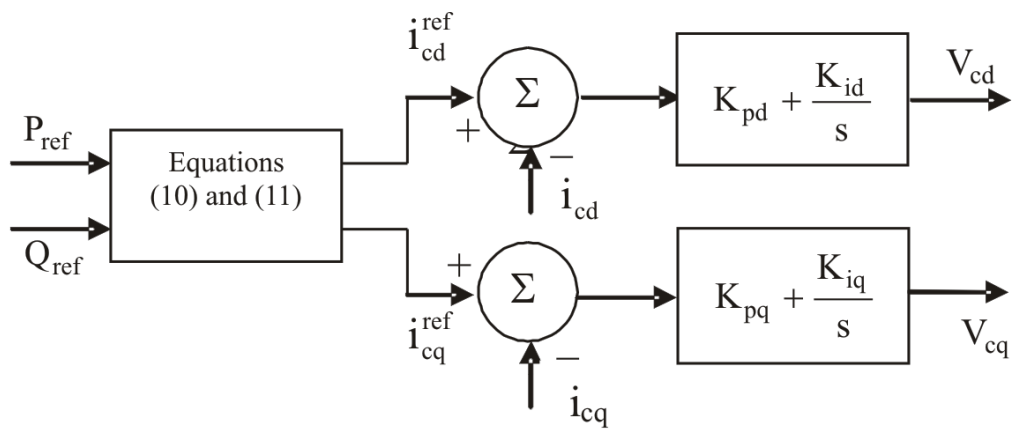

Figure 4. Series inverter control structure for UPFC

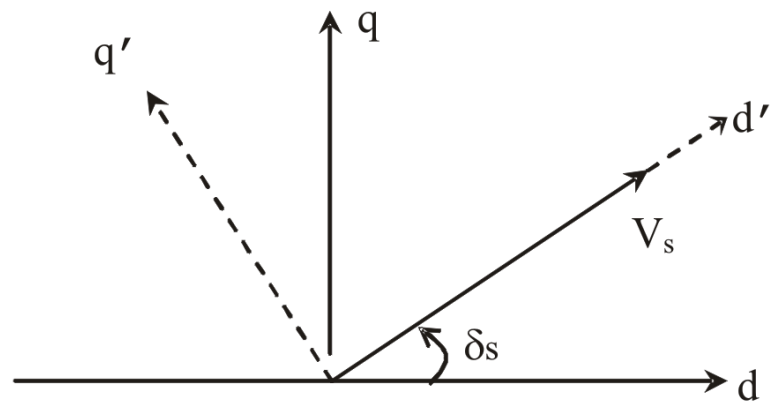

Figure 5. Phasor diagram showing $d-q$ and $d^{\prime}-q^{\prime}$ frame 


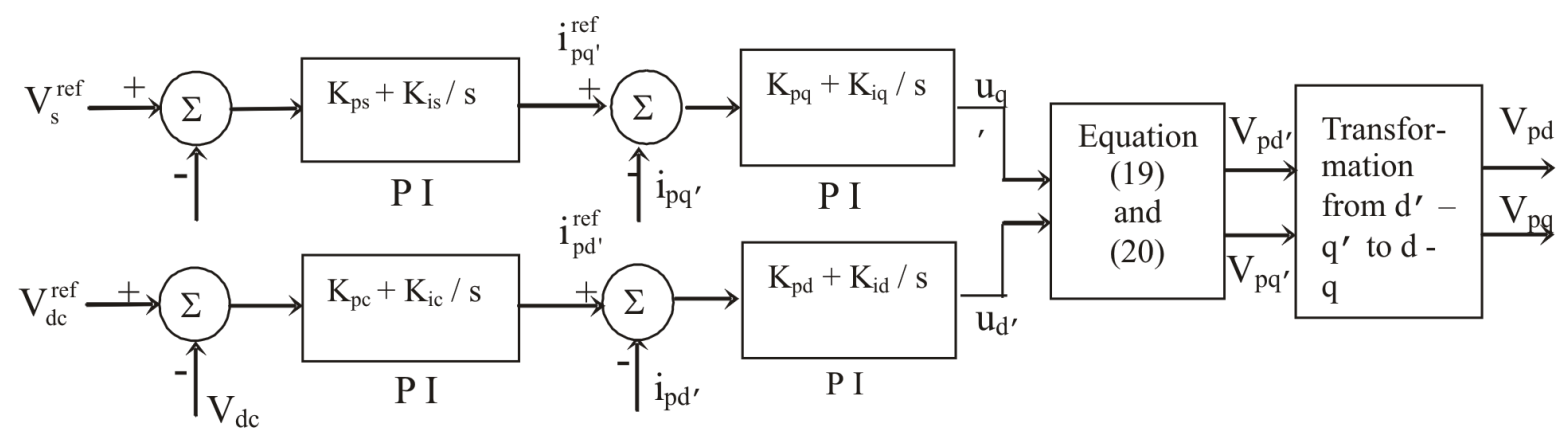

Figure 6. Shunt inverter control structure for UPFC

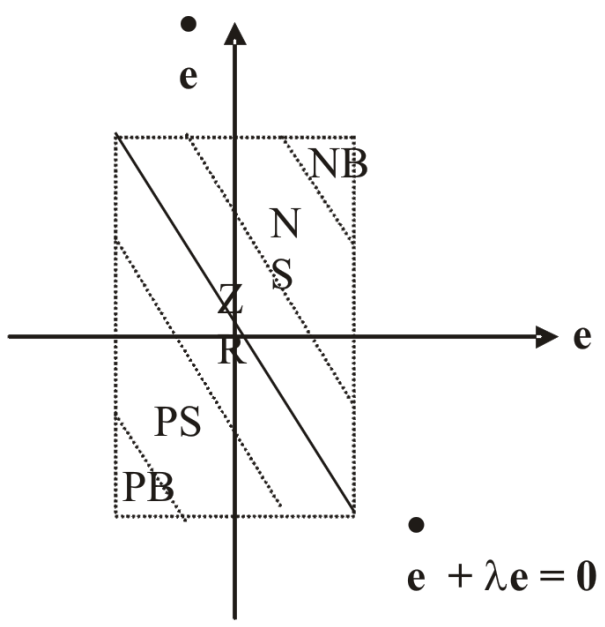

Figure 7. Rule Table with infinitesimal quantization levels

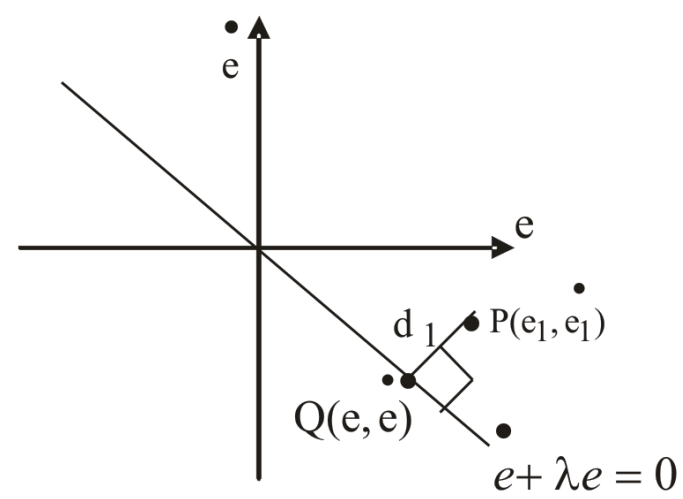

Figure 8 . Derivation of the signed distance 

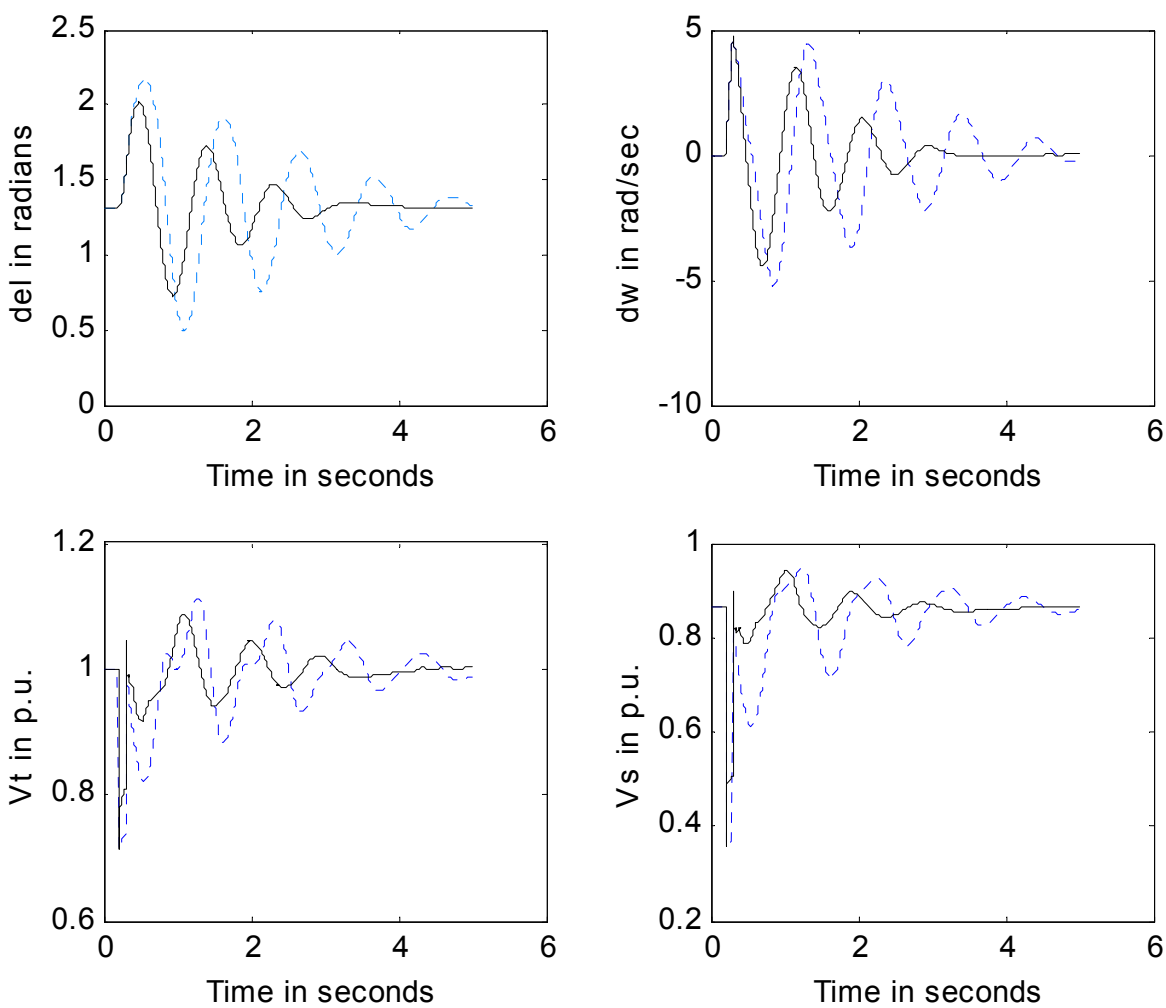

Figure 9. Comparison of transient performances for three phase fault applied at infinite bus at $0.2 \mathrm{sec}$ and cleared at $0.3 \sec (\mathrm{P}=1.2$ p.u., $\mathrm{Q}=0.85$ p.u. $) \mathrm{NO} \operatorname{UPFC}(---), \mathrm{UPFC} P I(-)$. 

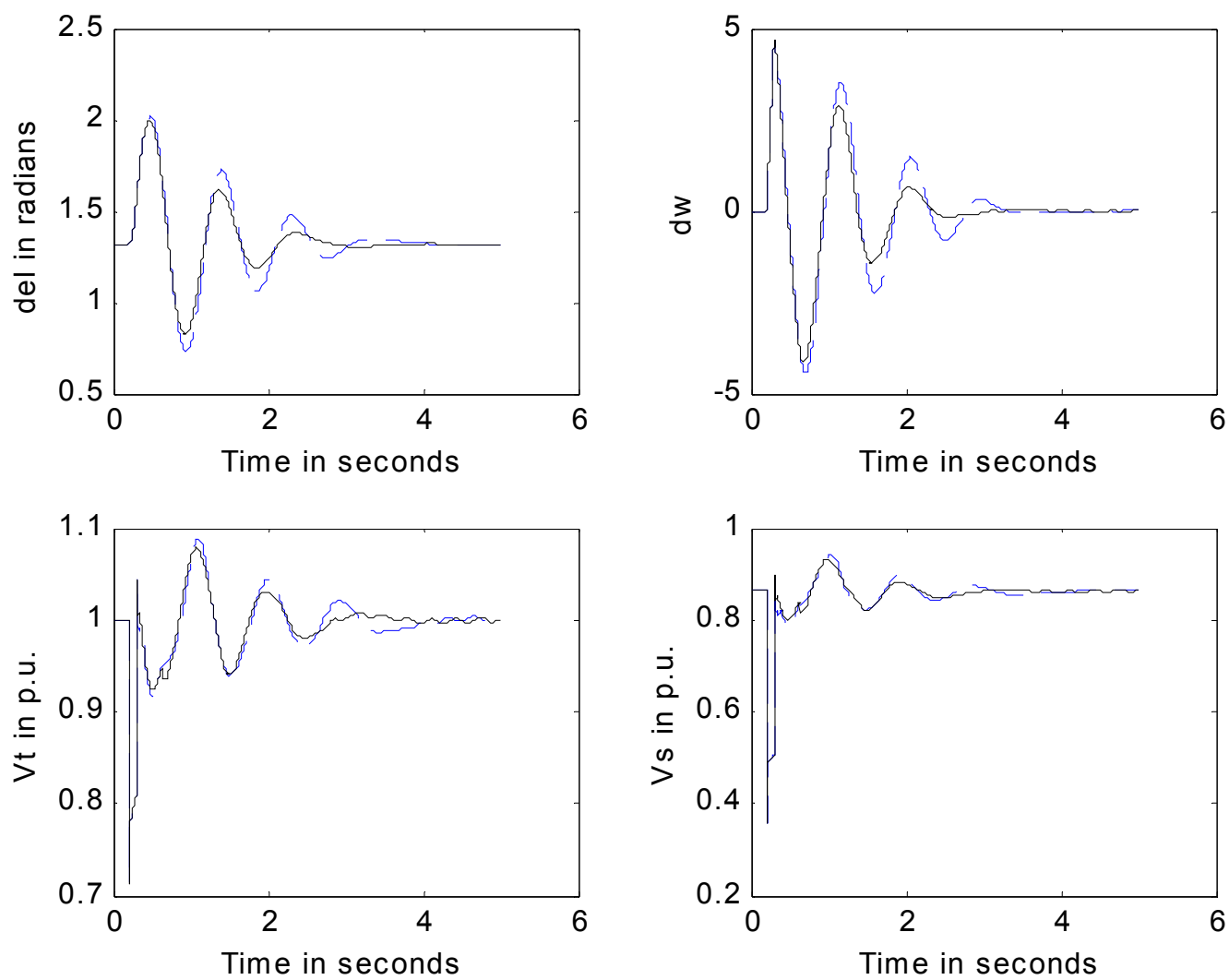

Figure 10. Comparison of transient performances for three phase fault applied at infinite bus at 0.2 sec And cleared at $0.3 \sec (\mathrm{P}=1.2$ p.u., $\mathrm{Q}=0.85$ p.u.) $\operatorname{UPFC}$ PI (---), $\operatorname{UPFC~SFLC~(~-~).~}$
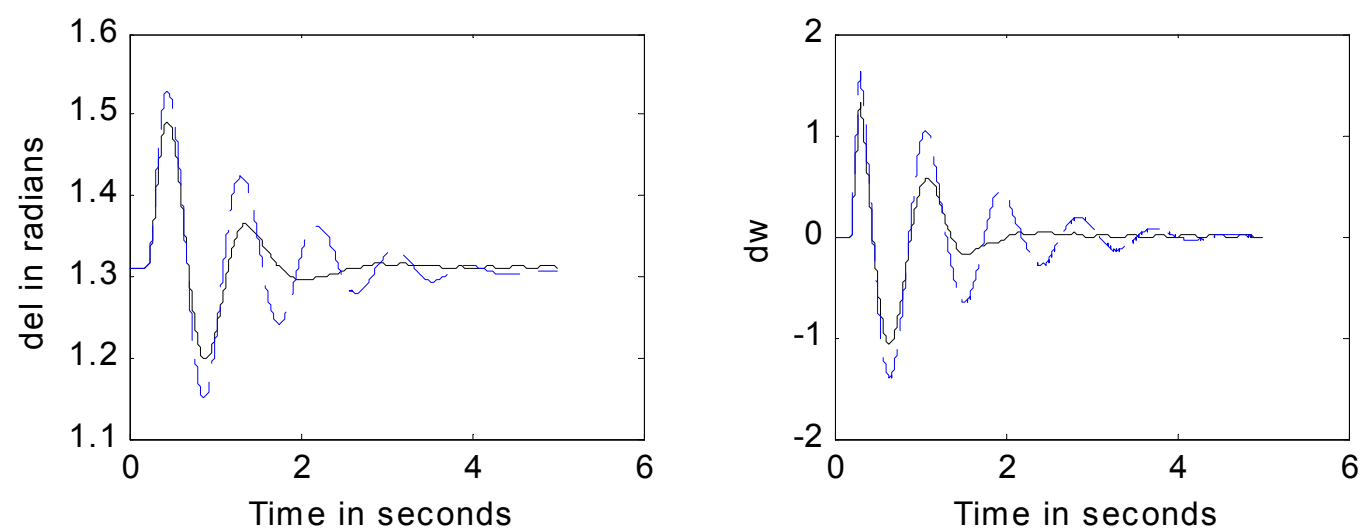

Figure 11. Comparison of transient performances for $50 \%$ line switching occurred at $0.2 \mathrm{sec}$ and cleared at $0.3 \sec (\mathrm{P}=1.2$ p.u., $\mathrm{Q}=0.85$ p.u. $) \quad$ UPFC PI (---), UPFC SFLC (-). 